\title{
Determinants of health-related quality of life in Iranian adults: evidence from a cross-sectional study
}

\author{
Satar Rezaei', Mohammad Hajizadeh², Ali Kazemi' ', Masoud Khosravipour ${ }^{3}$, Farid Khosravi³ \\ Shahab Rezaeian ${ }^{1}$

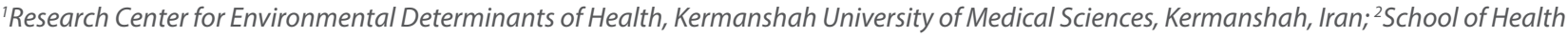 \\ Administration, Faculty of Health, Dalhousie University, Halifax, Canada; ${ }^{3}$ Student Research Committee, Kermanshah University of Medical \\ Sciences, Kermanshah, Iran
}

OBJECTIVES: This study aimed to measure the level and determinants of health-related quality of life (HRQoL) in adults in Kermanshah, a city in the western region of Iran.

METHODS: Convenience sampling was employed to obtain a sample of 998 adults aged 18 years and older (646 males and 352 females) in the city of Kermanshah. A 2-part self-administered questionnaire was used to collect data over the period between March 1 and May 30, 2017. The first part was designed to collect information on socio-demographic characteristics, socioeconomic status, and lifestyle factors (10 items). The second part consisted of the EuroQoL 5-dimensions (EQ-5D) EuroQoL-3-level and the EuroQoL visual analog scale (EQ-VAS) questions. A multiple linear regression model was used to determine the factors associated with the EQ-5D index and EQ-VAS score among study participants.

RESULTS: The mean values for the EQ-5D index and the EQ-VAS score were 0.74 (standard deviation [SD], 0.19) and 80.9 (SD, 16.5), respectively. The highest percentage of self-reported problems ('some' and 'severe' problems) across the 5 dimensions of the EQ-5D index were associated with the dimensions of anxiety/depression (35.3\%) and pain/discomfort (32.9\%). The percentage of self-reported problems for the dimensions of usual activities, mobility, and self-care were 19.0, 12.8, and 8.9\%, respectively. Our regression analyses indicated that there were statistically significant positive associations between being physically active, monthly household income per capita, and post-secondary education and the EQ-5D index and EQ-VAS score. In contrast, negative associations were found between older age, being married, having a chronic disease, and smoking and the EQ-5D index and EQ-VAS score. A negative association was also found between being uninsured and the EQ-5D index.

CONCLUSIONS: Our findings suggest that interventions aiming to improve physical activity, to prevent chronic diseases, and to reduce the smoking rate among adults living in the city of Kermanshah may improve their HRQoL.

KEY WORDS: Quality of life, Adult, Visual analog scale, Iran

\section{Correspondence: Shahab Rezaeian}

Research Center for Environmental Determinants of Health,

Kermanshah University of Medical Sciences, Isar Square,

Kermanshah 6719851351, Iran

E-mail: Shahab.Rezayan@gmail.com

Received: Jul 22, 2017 / Accepted: Aug 15, 2017 / Published: Aug 15, 2017

This article is available from: http://e-epih.org/

(C) This is an open-access article distributed under the terms of the Creative Commons Attribution License (http://creativecommons.org/licenses/by/4.0/), which permits unrestricted use, distribution, and reproduction in any medium, provided the original work is properly cited.

(C) 2017, Korean Society of Epidemiology

\section{INTRODUCTION}

Ensuring an equal distribution of health-related quality of life (HRQoL) across different social groups and regions is important for policymakers. Hence, measuring and monitoring HRQoL in the general population is critical for developing appropriate health policy interventions to reduce social and geographical inequality in HRQoL throughout society [1,2]. Population-level studies that aim to measure the level and determinants of quality of life (QoL) can potentially provide valuable information about HRQoL across different socio-demographic and socioeconomic groups [2].

The level and determinants of HRQoL in the general population 
have been well documented in developed countries such as Sweden [1], Netherlands [3], Norway [4], the UK [5], the US [6], and Japan [7]. There are, however, few studies on HRQoL in developing countries. To date, some studies in Iran have investigated QoL in specific population groups. For example, Tajvar and colleagues [8] examined HRQoL and its determinants in the elderly population of Tehran, Iran. Other studies have investigated HRQoL in the elderly in different regions of Iran $[9,10]$. Some studies have also focused on QoL in specific patient groups, such as patients with multiple sclerosis [11], diabetes [12,13], thalassemia [14], coronary artery disease [15], and tuberculosis [16]. Another study by Karyani et al. [17] examined HRQoL and it determinants among individuals with health insurance coverage in Tehran, Iran. That study showed that factors such as sex, age, educational attainment, income, having a chronic disease, and body mass index (BMI) had significant impacts on the QoL of insured people. Furthermore, a study by Ghafari et al. [18] likewise suggested that sex, place of residence, and educational attainment had a significant influence on the QoL of individuals living in the city of Qom, Iran.

Thus, to date, only a limited number of studies have investigated HRQoL in Iran. There is even less evidence on the level and determinants of HRQoL in the general population of Iran $[18,19]$. In this study, we aimed at filling this gap by investigating HRQoL in the city of Kermanshah, located in the western part of Iran. We used the EuroQoL 5-dimensions scale (EQ-5D; one of the popular general instruments for measuring HRQoL) and the EuroQoL visual analog scale (EQ-VAS) to examine the level and determinants of HRQoL in adults in Kermanshah. Understanding the determinants of HRQoL in the general population is important for designing and implementing policies to promote and improve the QoL of Iranian adults.

\section{MATERIALS AND METHODS}

\section{Study setting}

This study was conducted in the city of Kermanshah, the capital of Kermanshah Province. This province consists of 14 counties and is in the western region of Iran. The province is bordered by Kurdistan Province to the north, Hamadan and Lorestan Provinces to the east and Ilam Province to the south. It is also bordered by Iraq to the west. The total population of the province was estimated to be approximately 2 million in 2015 .

\section{Study population and sampling method}

This was a cross-sectional study, carried out from March to May 2017 that measured HRQoL and its main determinants in adults aged 18 years and older in Kermanshah, Iran. We calculated the sample size using the following sample size calculation formula:

$$
n=\frac{Z^{2} \delta^{2}}{d^{2}}
$$

Where $n$ indicates the required sample size at a $95 \%$ level of sig- nificance ( $z=1.96), \delta$ denotes the standard deviation (SD) of the HRQoL scores, and $d$ is the degree of precision of the mean of HRQoL scores, which was set at 0.015 . The mean and SD values were obtained from a previous study conducted in Iran among the general population [18]. To increase the generalizability of the findings of this study, we added $25 \%$ more adults to the required sample size of 825 , and sampled 1,035 adults in the study. A total of 998 adults (646 males and 352 females) participated in the study, with a response rate of $96 \%$. Samples were selected in 2 stages. First, the city of Kermanshah was divided into northern, southern, western, eastern, and central areas. Then, equal samples from each area were selected by convenience sampling.

\section{Instrument and measurement}

A self-administered questionnaire with 2 parts was used for data collection. The first part included questions related to the sociodemographic characteristics (age, sex, marital status), socioeconomic status (household monthly income, educational attainment, having health insurance), and lifestyle factors (smoking behavior, physical activity, BMI, and having a chronic disease) of the study participants. The second part included a validated Iranian version of the EQ-5D-3level (EQ-5D-3L) questionnaire [17]. The EQ5D-3L was introduced by the EuroQoL Group. As a standard questionnaire for measuring HRQoL, the EQ-5D-3L consists of 5 dimensions (mobility, self-care, usual activity, pain/discomfort, and anxiety/depression), with 3 response levels for each dimension (no problem, some problem, or extreme problem). The EQ-5D-3L also includes the EQ-VAS, which allows participants to rate their health status on a scale from 1 to 100 [20]. The Iranian value set for EQ-5D-3L health states, calculated by the VAS method in a recent study conducted by Goudarzi et al. [21], was used to compute the HRQoL of participants.

\section{Statistical analysis}

We used the Kolmogorov-Smirnov test to examine the normality of the data distribution. The t-test and analysis of variance were used to identify significant differences in the mean EQ-5D index and EQ-VAS score according to explanatory variables. The EQ$5 \mathrm{D}$ index and EQ-VAS score were used as outcome variables. We used age, sex, marital status, monthly household income per capita, educational attainment, having health insurance, physical activity, smoking behavior, BMI, and having a chronic disease as explanatory variables. The BMI was computed as weight in kilograms divided by height in meters squared $\left(\mathrm{kg} / \mathrm{m}^{2}\right)$. Following World Health Organization recommendations, participants were classified into 3 groups based on their BMIs: normal weight $(<25 \mathrm{~kg}$ / $\mathrm{m}^{2}$ ), overweight $\left(25-30 \mathrm{~kg} / \mathrm{m}^{2}\right)$, and obese $\left(\geq 30 \mathrm{~kg} / \mathrm{m}^{2}\right)$. Respondents were classified into 3 groups based on their smoking behavior: current smokers (if they smoked at least one cigarette per day), former smokers (if they smoked regularly or occasionally in the past), and never smokers (if they never smoked or had smoked fewer than 100 cigarettes in their lifetime). Multiple linear regression was employed to determine the main determinants of the 
EQ-5D index and EQ-VAS score. Variance inflation factors and the tolerance index were used to check for collinearity among the explanatory variables. The $\mathrm{p}$-values $<0.05$ were considered to indicate statistical significance. All analyses were performed using the statistical package Stata version 14.2 (StataCorp., College Station, TX, USA).

\section{Ethical issues}

This study was approved by the Ethics Committee of the Deputy of Research of the Kermanshah University of Medical Sciences (KUMS.REC.1396.240). Participants were assured that their personal information and answers would remain confidential.

Table 1. The average EQ-5D index and EQ-VAS scores by socio-demographic characteristics, socioeconomic status, and lifestyle factors in the study population

\begin{tabular}{|c|c|c|c|c|c|}
\hline Variables & Frequency (\%) & EQ-5D & p-value & EQ-VAS & p-value \\
\hline \multicolumn{6}{|l|}{ Age (yr) } \\
\hline $18-44$ & $771(77.2)$ & $0.78 \pm 0.16$ & \multirow[t]{2}{*}{$<0.001^{1}$} & $83.4 \pm 15.1$ & \multirow[t]{2}{*}{$<0.001$} \\
\hline$\geq 45$ & $227(22.8)$ & $0.63 \pm 0.23$ & & $72.4 \pm 18.4$ & \\
\hline \multicolumn{6}{|l|}{ Sex } \\
\hline Male & $646(64.7)$ & $0.74 \pm 0.19$ & \multirow[t]{2}{*}{$0.83^{1}$} & $80.1 \pm 16.1$ & \multirow[t]{2}{*}{$0.03^{1}$} \\
\hline Female & $352(35.3)$ & $0.75 \pm 0.19$ & & $82.4 \pm 17.2$ & \\
\hline \multicolumn{6}{|l|}{ Marital status } \\
\hline Never married & $471(47.2)$ & $0.79 \pm 0.15$ & \multirow[t]{3}{*}{$<0.001^{2}$} & $84.7 \pm 14.6$ & \multirow[t]{3}{*}{$<0.001^{2}$} \\
\hline Married & $480(48.1)$ & $0.71 \pm 0.21$ & & $78.0 \pm 16.9$ & \\
\hline Divorced and widowed & $47(4.7)$ & $0.61 \pm 0.24$ & & $72.3 \pm 21.5$ & \\
\hline \multicolumn{6}{|c|}{ Monthly household income per capita (IRR) ${ }^{3}$} \\
\hline Low (<10 million) & $531(53.2)$ & $0.74 \pm 0.19$ & \multirow[t]{3}{*}{$<0.001^{2}$} & $80.6 \pm 18.3$ & \multirow[t]{3}{*}{$<0.001^{2}$} \\
\hline Middle (10-20 million) & $344(34.5)$ & $0.73 \pm 0.20$ & & $79.0 \pm 14.1$ & \\
\hline High (>2 million) & $123(12.3)$ & $0.79 \pm 0.15$ & & $87.6 \pm 13.2$ & \\
\hline \multicolumn{6}{|l|}{ Educational attainment } \\
\hline Illiterate & $33(3.3)$ & $0.51 \pm 0.26$ & \multirow[t]{3}{*}{$<0.001^{2}$} & $60.0 \pm 19.7$ & \multirow[t]{3}{*}{$<0.001^{2}$} \\
\hline Primary and secondary & $459(46.0)$ & $0.72 \pm 0.20$ & & $79.1 \pm 16.3$ & \\
\hline Post-secondary & $506(50.7)$ & $0.78 \pm 0.15$ & & $83.9 \pm 15.2$ & \\
\hline \multicolumn{6}{|l|}{ Health insurance } \\
\hline Yes & $828(83.0)$ & $0.75 \pm 0.19$ & \multirow[t]{2}{*}{$0.001^{1}$} & $81.3 \pm 15.5$ & \multirow[t]{2}{*}{$0.001^{1}$} \\
\hline No & $170(17.0)$ & $0.70 \pm 0.20$ & & $79.2 \pm 20.8$ & \\
\hline \multicolumn{6}{|l|}{ Smoking behavior } \\
\hline Current & $280(28.1)$ & $0.70 \pm 0.22$ & \multirow[t]{3}{*}{$<0.001^{2}$} & $73.2 \pm 15.5$ & \multirow[t]{3}{*}{$<0.001^{2}$} \\
\hline Former & $56(5.6)$ & $0.67 \pm 0.21$ & & $72.7 \pm 17.5$ & \\
\hline Never & $662(66.3)$ & $0.77 \pm 0.17$ & & $84.7 \pm 15.5$ & \\
\hline \multicolumn{6}{|l|}{ Physical activity } \\
\hline Active & $610(61.2)$ & $0.80 \pm 0.14$ & \multirow[t]{3}{*}{$<0.001^{2}$} & $86.4 \pm 12.2$ & \multirow[t]{3}{*}{$<0.001^{2}$} \\
\hline Moderately active & $283(28.3)$ & $0.69 \pm 0.20$ & & $75.7 \pm 15.8$ & \\
\hline Inactive & $105(10.5)$ & $0.56 \pm 0.25$ & & $63.1 \pm 22.3$ & \\
\hline \multicolumn{6}{|l|}{ Body mass index } \\
\hline Normal & $564(56.5)$ & $0.76 \pm 0.18$ & \multirow[t]{3}{*}{$<0.001^{2}$} & $83.3 \pm 15.7$ & \multirow[t]{3}{*}{$<0.001^{2}$} \\
\hline Overweight & $367(36.8)$ & $0.73 \pm 0.20$ & & $78.1 \pm 16.7$ & \\
\hline Obese & $67(6.7)$ & $0.67 \pm 0.24$ & & $76.7 \pm 19.1$ & \\
\hline \multicolumn{6}{|l|}{ Chronic diseases } \\
\hline Yes & $131(13.1)$ & $0.56 \pm 0.22$ & $0.001^{1}$ & $63.5 \pm 18.9$ & $0.001^{1}$ \\
\hline No & 867 (86.9) & $0.77 \pm 0.17$ & & $83.5 \pm 14.4$ & \\
\hline
\end{tabular}

Values are presented as mean \pm standard deviation.

EQ-5D, EuroQoL 5-dimensions; EQ-VAS, EuroQoL visual analog scale; QoL, quality of life; IRR, Iranian rial.

${ }^{1}$ Statistical significance of differences calculated using the t-test.

${ }^{2}$ Statistical significance of differences calculated using analysis of variance.

${ }^{3}$ One US dollar = 35,000 IRR in 2017. 


\section{RESULTS}

The average age of the participants was 32.2 years, with a SD of 12.4 years. Most of the participants $(53.2 \%)$ fell into the low-income category (monthly household income per capita $<10$ million Iranian rials), $28.1 \%$ were current smokers, and $61.2 \%$ were physically active. Of the participants, $56.5 \%$ had a normal weight, while the remaining $43.5 \%$ were either overweight or obese. The mean values of the EQ-5D index and EQ-VAS score were 0.74 (SD, 0.19) and 80.9 (SD, 16.5), respectively. We observed a positive significant association between the EQ-5D index and EQ-
VAS score $(r=0.63 ; \mathrm{p}<0.001)$ in the sample. Table 1 presents the average EQ-5D index and EQ-VAS score in the study population according to socio-demographic characteristics, socioeconomic status, and lifestyle factors.

As shown in Table 1, statistically significant differences were found in the EQ-5D index and EQ-VAS score by age group, marital status, BMI, smoking behavior, physical activity, household monthly income per capita, educational attainment, having health insurance, and having a chronic disease $(\mathrm{p}<0.05)$. While we did not observe a significant difference in the EQ-5D index according to sex $(\mathrm{p}=0.83)$, the association between sex and the EQ-VAS score

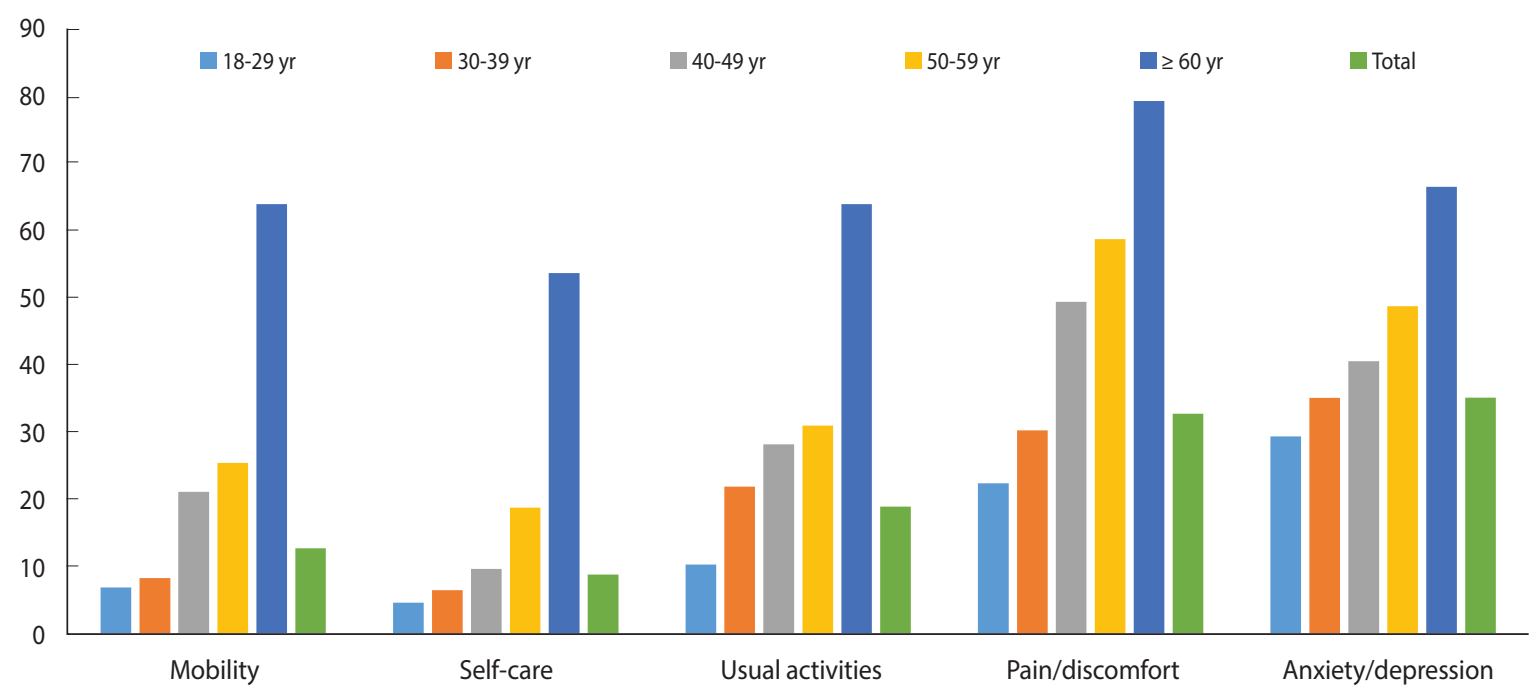

Figure 1. Percentage of respondents who reported problems ('some' or'severe') among the adult population by age group in Kermanshah, Iran, 2017.

Table 2. Detailed responses of participants to the 5 dimensions of the EQ-5D according to age group in Kermanshah, western Iran, 2017

\begin{tabular}{|c|c|c|c|c|c|c|c|}
\hline \multirow{2}{*}{ EQ-5D } & \multirow{2}{*}{$\begin{array}{c}\text { Level } \\
\text { (problem) }\end{array}$} & \multicolumn{5}{|c|}{ Age (yr) } & \multirow{2}{*}{ Tota } \\
\hline & & $18-29$ & $30-39$ & $40-49$ & $50-59$ & $\geq 60$ & \\
\hline \multirow[t]{3}{*}{ Mobility } & No & 93.0 & 91.6 & 78.8 & 74.4 & 35.9 & 87.2 \\
\hline & Some & 7.0 & 8.4 & 21.2 & 25.6 & 64.1 & 12.8 \\
\hline & Severe & 0.0 & 0.0 & 0.0 & 0.0 & 0.0 & 0.0 \\
\hline \multirow[t]{3}{*}{ Self-care } & No & 95.3 & 93.4 & 90.3 & 81.1 & 46.2 & 91.1 \\
\hline & Some & 4.7 & 6.6 & 9.7 & 18.9 & 53.8 & 8.9 \\
\hline & Severe & 0.0 & 0.0 & 0.0 & 0.0 & 0.0 & 0.0 \\
\hline \multirow[t]{3}{*}{ Usual activities } & No & 89.6 & 78.0 & 71.7 & 68.9 & 35.9 & 81.0 \\
\hline & Some & 10.4 & 22.0 & 28.3 & 31.1 & 64.1 & 19.0 \\
\hline & Severe & 0.0 & 0.0 & 0.0 & 0.0 & 0.0 & 0.0 \\
\hline \multirow[t]{3}{*}{ Pain/discomfort } & No & 77.5 & 69.6 & 50.4 & 41.1 & 20.5 & 67.1 \\
\hline & Some & 21.6 & 30.4 & 48.7 & 57.8 & 71.8 & 31.9 \\
\hline & Severe & 0.9 & 0.0 & 0.9 & 1.1 & 7.7 & 1.0 \\
\hline \multirow[t]{3}{*}{ Anxiety/depression } & No & 70.5 & 64.8 & 59.3 & 51.1 & 33.3 & 64.7 \\
\hline & Some & 28.2 & 33.0 & 37.2 & 45.6 & 56.4 & 33.0 \\
\hline & Severe & 1.3 & 2.2 & 3.5 & 3.3 & 10.3 & 2.3 \\
\hline
\end{tabular}

Values are presented as \%.

EQ-5D, EuroQoL 5-dimensions; QoL, quality of life. 
was statistically significant $(\mathrm{p}=0.03)$. Figure 1 and Table 2 present descriptive statistics for participants' detailed responses to the 5 EQ-5D dimensions by age groups. The highest percentage of reported problems ('some' or 'severe') across the 5 dimensions was associated with anxiety/depression (35.3\%), followed by pain/discomfort (32.9\%), usual activities (19.0\%), mobility (12.8\%), and self-care (8.9\%). None of the participants reported having 'severe' problems with mobility, self-care, or usual activities (Figure 1 and Table 2).

The results of multiple linear regression were presented in Table 3. The value of the variance inflation factors was 2.54 , indicating no multicollinearity among the independent variables. The results

Table 3. Multiple linear regression results of the association between explanatory variables and the EQ-5D index and EQ-VAS score

\begin{tabular}{|c|c|c|c|c|c|c|}
\hline \multirow{3}{*}{ Explanatory variables } & \multicolumn{6}{|c|}{ Dependent variables } \\
\hline & \multicolumn{3}{|c|}{ EQ-5D } & \multicolumn{3}{|c|}{ EQ-VAS } \\
\hline & Coefficient & p-value & $95 \% \mathrm{Cl}$ & Coefficient & $\mathrm{p}$-value & $95 \% \mathrm{Cl}$ \\
\hline \multicolumn{7}{|l|}{ Age (yr) } \\
\hline $18-44$ & Reference & & & Reference & & \\
\hline$\geq 45$ & -0.07 & 0.00 & $-0.09,-0.04$ & -3.40 & 0.005 & $-5.70,-1.02$ \\
\hline \multicolumn{7}{|l|}{ Sex } \\
\hline Male & Reference & & & Reference & & \\
\hline Female & 0.01 & 0.28 & $-0.01,0.04$ & 1.55 & 0.12 & $-0.41,3.53$ \\
\hline \multicolumn{7}{|l|}{ Marital status } \\
\hline Never married & Reference & & & Reference & & \\
\hline Married & -0.02 & 0.07 & $-0.04,0.00$ & -2.20 & 0.02 & $-4.20,-0.29$ \\
\hline Divorced and widowed & -0.07 & 0.006 & $-0.12,-0.02$ & -2.70 & 0.20 & $-6.80,1.40$ \\
\hline \multicolumn{7}{|c|}{ Monthly household income per capita (IRR) ${ }^{1}$} \\
\hline \multicolumn{7}{|c|}{ Low (<10 million) } \\
\hline Middle (10-20 million) & 0.012 & 0.33 & $-0.01,0.04$ & 1.40 & 0.15 & $-0.53,3.30$ \\
\hline High (>2 million) & 0.06 & 0.00 & $0.03,0.01$ & 8.54 & 0.00 & $5.80,11.30$ \\
\hline \multicolumn{7}{|l|}{ Educational level } \\
\hline Illiterate & Reference & & & Reference & & \\
\hline Primary and secondary & 0.04 & 0.15 & $-0.02,0.10$ & 5.50 & 0.02 & $0.66,10.40$ \\
\hline Post-secondary & 0.07 & 0.04 & $0.00,0.13$ & 5.40 & 0.03 & $0.41,10.40$ \\
\hline \multicolumn{7}{|l|}{ Health insurance } \\
\hline Yes & Reference & & & Reference & & \\
\hline No & -0.04 & 0.01 & $-0.06,-0.01$ & -1.33 & 0.24 & $-3.60,0.90$ \\
\hline \multicolumn{7}{|l|}{ Smoking behavior } \\
\hline Never & Reference & & & Reference & & \\
\hline Former & -0.06 & 0.00 & $-0.10,-0.02$ & -8.80 & 0.00 & $-12.40,-5.20$ \\
\hline Current & -0.03 & 0.00 & $-0.06,-0.01$ & -8.80 & 0.00 & $-10.90,-6.70$ \\
\hline \multicolumn{7}{|l|}{ Physical activity } \\
\hline Inactive & Reference & & & Reference & & \\
\hline Moderately active & 0.09 & 0.00 & $0.05,0.13$ & 15.90 & 0.00 & $13.00,18.70$ \\
\hline Active & 0.15 & 0.00 & $0.12,0.19$ & 8.90 & 0.00 & $5.90,11.90$ \\
\hline \multicolumn{7}{|l|}{ Body mass index } \\
\hline Normal & Reference & & & Reference & & \\
\hline Overweight & -0.002 & 0.87 & $-0.02,0.02$ & -1.90 & 0.03 & $-3.70,-0.19$ \\
\hline Obese & -0.02 & 0.31 & $-0.06,0.02$ & -2.10 & 0.21 & $-5.50,1.20$ \\
\hline \multicolumn{7}{|l|}{ Chronic diseases } \\
\hline Yes & Reference & & & Reference & & \\
\hline No & 0.11 & 0.00 & $0.08,0.15$ & 11.30 & 0.00 & $8.70,13.90$ \\
\hline R-squared (\%) & & 31.00 & & & 41.50 & \\
\hline Adjusted R-squared (\%) & & 29.90 & & & 40.00 & \\
\hline Prob $>F$ & & 0.00 & & & 0.00 & \\
\hline
\end{tabular}

EQ-5D, EuroQoL 5-dimensions; EQ-VAS, EuroQoL visual analog scale; QoL, quality of life; IRR, Iranian rial; Cl, confidence interval.

'One US dollar = 35,000 IRR in 2017. 
suggested that the independent variables explained approximately 31.00 and $41.50 \%$ of the variance in the EQ-5D index and EQ-VAS score, respectively. Statistically significant positive associations were found between being physically active, household monthly income per capita, and post-secondary educational attainment and the EQ-5D index and EQ-VAS score. In contrast, significant negative associations were observed between older age, being married, having a chronic disease, and being a current or former smoker and the EQ-5D index and EQ-VAS score. No significant association was found between sex and the EQ-5D index. We only observed a negative association between being overweight and the EQ-VAS score. In addition, a negative association was found between being uninsured and the EQ-5D index.

\section{DISCUSSION}

Measuring HRQoL among the general population is an important issue for health policymakers and is critical for the development of appropriate interventions to improve the QoL of individuals within society. This study used the EQ-5D-3L questionnaire to measure HRQoL and its main determinants among the general population of the city of Kermanshah, Iran, in 2017. Pain/discomfort and anxiety/depression were the most common health problems among the general population in Kermanshah. These findings are similar to the findings of previous studies in Iran [17] and other countries [22,23]. One of the potential factors contributing to the higher proportion of these 2 health problems in Kermanshah is the high unemployment rate of $23.2 \%$ in this province [24], which leads to a lower QoL among adults living in this city.

We found that having a chronic disease was associated with poor HRQoL, based on both the EQ-5D index and the EQ-VAS score. Several studies have indicated that chronic diseases such as hypertension [25], diabetes [26], coronary heart disease [15], tuberculosis [16], multiple sclerosis [27], cancers [28], and allergic diseases [29] reduce HRQoL among adults. A study by Karyani et al. [17] showed that chronic disease was an important determinant of HRQoL in Iran. That study suggested that the prevention and management of chronic diseases should be a priority for improving HRQoL in Iran. Similar to the study by Karyani et al. [17], our study indicated that having health insurance was significantly positively related with the EQ-5D index. The positive impact of having health insurance coverage on HRQoL can be explained by improved access to appropriate and timely healthcare services.

We also found that risky behaviors such as smoking and being physically inactive were significantly associated with a poor EQ5D index and EQ-VAS score. The current literature [30] suggests that individuals who engage in risky behaviors pay less attention to their health, contributing to the onset of chronic diseases that, in turn, reduce HRQoL among this population group. Studies from other countries have demonstrated that ceasing risky behaviors leads to a higher HRQoL among the adult population. For example, a study in Spain [31] reported that former smokers had better health scores than their smoking counterparts. As a result, educa- tional and preventive programs are required to reduce risky behaviors among these groups within society. Although being obese has been shown to have a negative influence on HRQoL [26], we did not observe a significant relationship between obesity and HRQoL in our study.

Moreover, our findings showed that aging had a negative effect on HRQoL. Iran's population is aging [32], which presents challenges for policymakers to improve the QoL of older adults in Iran. Aghamolaei et al. [10] examined the HRQoL of older adults in Bandar Abas (the southern region of Iran) and reported that it was lower in older adults. Similarly to that study [10], we found that higher levels of educational attainment were associated positively with HRQoL among adults. In addition, we found a significant positive relationship between monthly household income per capita and HRQoL in the adult population. Income, as an indicator of socioeconomic status, is associated with healthcare-seeking behaviors, which can affect the QoL of adults. In fact, previous studies $[33,34]$ have already demonstrated higher utilization of healthcare services among higher socioeconomic status groups in Iran.

Our study is subject to some limitations. First, we were unable to establish causal relationships between the explanatory and dependent variables due to the cross-sectional design of this study. Second, the results related to some of the self-reported variables, such as monthly household income per capita, should be interpreted with caution. Lastly, the use of a non-random sampling method in the study may limit the generalizability of the findings. Even considering these caveats, the results of our study suggest that health policymakers should focus on the effects of the major lifestyle and socioeconomic factors affecting HRQoL to improve the QoL among the general population in Iran. Nonetheless, further studies are required to determine the most effective interventions to improve the HRQoL of Iranian adults.

In summary, our study demonstrated the effects of socio-demographic characteristics, socioeconomic status, and lifestyle factors on HRQoL among the general population of adults living in Kermanshah, western Iran. The results suggested that interventions aiming to increase physical activity, to prevent and manage chronic diseases, and to reduce the smoking rate among Iranian adults may improve their HRQoL.

\section{ACKNOWLEDGEMENTS}

This study was extracted from a project approved by the Kermanshah University of Medical Sciences. The study was funded and supported by the Research Deputy of Kermanshah University of Medical Sciences.

\section{CONFLICT OF INTEREST}

The authors have no conflicts of interest to declare for this study. 


\section{ORCHID}

Satar Rezaei: http://orcid.org/0000-0002-6194-6057; Mohammad Hajizadeh: http://orcid.org/0000-0003-0029-6449; Ali Kazemi: http: //orcid.org/0000-0001-8351-5250; Masoud Khosravipour: http://orcid.org/0000-0003-2444-5146; Farid Khosravi: http://orcid.org/0000-0003-0958-7330; Shahab Rezaeian: http://orcid.org/0000-0002-5094-5315

\section{REFERENCES}

1. Burström K, Johannesson M, Diderichsen F. Swedish population health-related quality of life results using the EQ-5D. Qual Life Res 2001;10:621-635.

2. Burström K, Johannesson M, Diderichsen F. Health-related quality of life by disease and socio-economic group in the general population in Sweden. Health Policy 2001;55:51-69.

3. Terwindt GM, Ferrari MD, Tijhuis M, Groenen SM, Picavet HS, Launer LJ. The impact of migraine on quality of life in the general population: the GEM study. Neurology 2000;55:624-629.

4. Wahl AK, Rustøen T, Rokne B, Lerdal A, Knudsen Ø, Miaskowski $\mathrm{C}$, et al. The complexity of the relationship between chronic pain and quality of life: a study of the general Norwegian population. Qual Life Res 2009;18:971-980.

5. Kind P, Dolan P, Gudex C, Williams A. Variations in population health status: results from a United Kingdom national questionnaire survey. BMJ 1998;316:736-741.

6. Johnson JA, Coons SJ, Ergo A, Szava-Kovats G. Valuation of EuroQOL (EQ-5D) health states in an adult US sample. Pharmacoeconomics 1998;13:421-433.

7. Hisashige A, Mikasa H, Katayama T. Description and valuation of health-related quality of life among the general public in Japan by the EuroQol. J Med Invest 1998;45:123-129.

8. Tajvar M, Arab M, Montazeri A. Determinants of health-related quality of life in elderly in Tehran, Iran. BMC Public Health 2008; 8:323.

9. Nejati V, Ashayeri $\mathrm{H}$. Health related quality of life in the elderly in Kashan. Iran J Psychiatry Clin Psychol 2008;14:56-61 (Persian).

10. Aghamolaei T, Tavafian SS, Zare S. Health related quality of life in elderly people living in Bandar Abbas, Iran: a populationbased study. Acta Med Iran 2010;48:185-191.

11. Kargarfard M, Eetemadifar M, Mehrabi M, Maghzi AH, Hayatbakhsh MR. Fatigue, depression, and health-related quality of life in patients with multiple sclerosis in Isfahan, Iran. Eur J Neurol 2012;19:431-437.

12. Aghamollaei T, Eftekhar H, Shojaeizadeh D, Mohammad K, Nakhjavani M, Pour FG. Behavior, metabolic control and health-related quality of life in diabetic patients at Bandar Abbas diabetic clinic. Iran J Public Health 2003;32:54-59.

13. Sanjari M, Safari S, Shokoohi M, Safizade H, Rashidinezhad H, Mashrouteh M, et al. A cross-sectional study in Kerman, Iran, on the effect of diabetic foot ulcer on health-related quality of life. Int J Low Extrem Wounds 2011;10:200-206.
14. Maheri A, Sadeghi R, Shojaeizadeh D, Tol A, Yaseri M, Ebrahimi M. Associations between a health-promoting lifestyle and quality of life among adults with beta-thalassemia major. Epidemiol Health 2016;38:e2016050.

15. Tofighi S, Ahmad Kiadaliri A, Sadeghifar J, Raadabadi M, Mamikhani J. Health-related quality of life among patients with coronary artery disease: a post-treatment follow-up study in Iran. Cardiol Res Pract 2012;2012:973974.

16. Mamani M, Majzoobi MM, Ghahfarokhi SM, Esna-Ashari F, Keramat F. Assessment of health-related quality of life among patients with tuberculosis in Hamadan, Western Iran. Oman Med J 2014; 29:102-105.

17. Karyani AK, Rashidian A, Sefiddashti SE, Sari AA. Self-reported health-related quality of life (HRQoL) and factors affecting HRQoL among individuals with health insurance in Iran. Epidemiol Health 2016;38:e2016046.

18. Ghafari R, Rafiei M, Taheri Nejad MR. Assessment of health related quality of life by SF-36 version 2 in general population of Qom City. Arak Med Univ J 2014;16:63-72 (Persian).

19. Nedjat S, Holakouie Naieni K, Mohammad K, Majdzadeh R, Montazeri A. Quality of life among an Iranian general population sample using the World Health Organization's quality of life instrument (WHOQOL-BREF). Int J Public Health 2011;56:55-61.

20. van Reenen M, Oppe M. EQ-5D-3L user guide: basic information on how to use the EQ-5D-3L instrument; 2015 [cited 2017 Aug 29]. Available from: https://euroqol.org/wp-content/uploads/ 2016/09/EQ-5D-3L_UserGuide_2015.pdf.

21. Goudarzi R, Zeraati H, Akbari Sari A, Rashidian A, Mohammad K. Population-based preference weights for the EQ-5D health states using the visual analogue scale (VAS) in Iran. Iran Red Crescent Med J 2016;18:e21584.

22. Marra CA, Woolcott JC, Kopec JA, Shojania K, Offer R, Brazier JE, et al. A comparison of generic, indirect utility measures (the HUI2, HUI3, SF-6D, and the EQ-5D) and disease-specific instruments (the RAQoL and the HAQ) in rheumatoid arthritis. Soc Sci Med 2005;60:1571-1582.

23. Zimmermann IR, Silva MT, Galvao TF, Pereira MG. Health-related quality of life and self-reported long-term conditions: a population-based survey. Rev Bras Psiquiatr 2017;39:62-68.

24. Babaie MH. Inequities in health and health care between provinces of Iran: promoting equitable health care resource allocation [dissertation]. Salford: University of Salford; 2012.

25. Kitaoka M, Mitoma J, Asakura H, Anyenda OE, Nguyen TT, Hamagishi $\mathrm{T}$, et al. The relationship between hypertension and healthrelated quality of life: adjusted by chronic pain, chronic diseases, and life habits in the general middle-aged population in Japan. Environ Health Prev Med 2016;21:193-214.

26. Hajian-Tilaki K, Heidari B, Hajian-Tilaki A. Solitary and combined negative influences of diabetes, obesity and hypertension on health-related quality of life of elderly individuals: a population-based cross-sectional study. Diabetes Metab Syndr 2016;10: S37-S42.

27. Amtmann D, Bamer AM, Kim J, Chung H, Salem R. People with 
multiple sclerosis report significantly worse symptoms and health related quality of life than the US general population as measured by PROMIS and NeuroQoL outcome measures. Disabil Health J 2017. doi: https://doi.org/10.1016/j.dhjo.2017.04.008.

28. Augustussen M, Sjøgren P, Timm H, Hounsgaard L, Pedersen ML. Symptoms and health-related quality of life in patients with advanced cancer - a population-based study in Greenland. Eur J Oncol Nurs 2017;28:92-97.

29. Hedman L, Stridsman C, Andersson M, Backman H, Jansson SA, Rönmark E. Population-based study shows that teenage girls with asthma had impaired health-related quality of life. Acta Paediatr 2017;106:1128-1135.

30. Yong HH, Borland R, Hammond D, Thrasher JF, Cummings KM, Fong GT. Smokers' reactions to the new larger health warning la- bels on plain cigarette packs in Australia: findings from the ITC Australia project. Tob Control 2016;25:181-187.

31. de Lossada A, Rejas J. Health-related quality-of-life in the smoking general population of Spain: an approach from the National Health Survey. Semergen 2016;42:431-439.

32. Noroozian M. The elderly population in iran: an ever growing concern in the health system. Iran J Psychiatry Behav Sci 2012; 6:1-6.

33. Esmailnasab N, Hassanzadeh J, Rezaeian S, Barkhordari M. Use of health care services and associated factors among women. Iran J Public Health 2014;43:70-78.

34. Hajizadeh M, Connelly LB, Butler JR, Khosravi A. Unmet need and met unneed in health care utilisation in Iran. Int J Soc Econ 2012;39:400-422. 